Supplement of Hydrol. Earth Syst. Sci., 25, 2399-2417, 2021

https://doi.org/10.5194/hess-25-2399-2021-supplement

(c) Author(s) 2021. CC BY 4.0 License.

(c) (i)

Supplement of

\title{
Global ecosystem-scale plant hydraulic traits retrieved using model-data fusion
}

Yanlan Liu et al.

Correspondence to: Yanlan Liu (liu.9367@osu.edu)

The copyright of individual parts of the supplement might differ from the article licence. 


\begin{tabular}{c|c}
\hline Parameter & Prior \\
\hline$g_{1}\left(\mathrm{kPa}^{1 / 2}\right)$ & Uniform $(0,10)$ \\
$C\left(\mathrm{~mm} \mathrm{MPa}^{-1}\right)$ & Uniform $(0,25)$ \\
$\psi_{50, s}(\mathrm{MPa})$ & Uniform $\left(\psi_{50, x}, 0\right)$ \\
$g_{p, \text { max }}\left(\mathrm{mm} \mathrm{hr}^{-1} \mathrm{MPa}^{-1}\right)$ & Uniform $(0,10)$ \\
$\psi_{50, x}(\mathrm{MPa})$ & Fig. S1 \\
$b_{0}($ unitless $)$ & Uniform $(0,10)$ \\
$b_{c}($ unitless $)$ & Uniform $(0,1)$ \\
$\sigma_{\mathrm{VOD}}($ unitless $)$ & Uniform $(0,0.2)$ \\
$\sigma_{\mathrm{SM}}\left(\mathrm{m}^{3} \mathrm{~m}^{-3}\right)$ & Uniform $(0,0.2)$ \\
$\sigma_{\mathrm{ET}}\left(\mathrm{mm} \mathrm{day}^{-1}\right)$ & Uniform $(0,2)$ \\
\hline
\end{tabular}

Table S1. Priors of model parameters jointly sampled using MCMC.
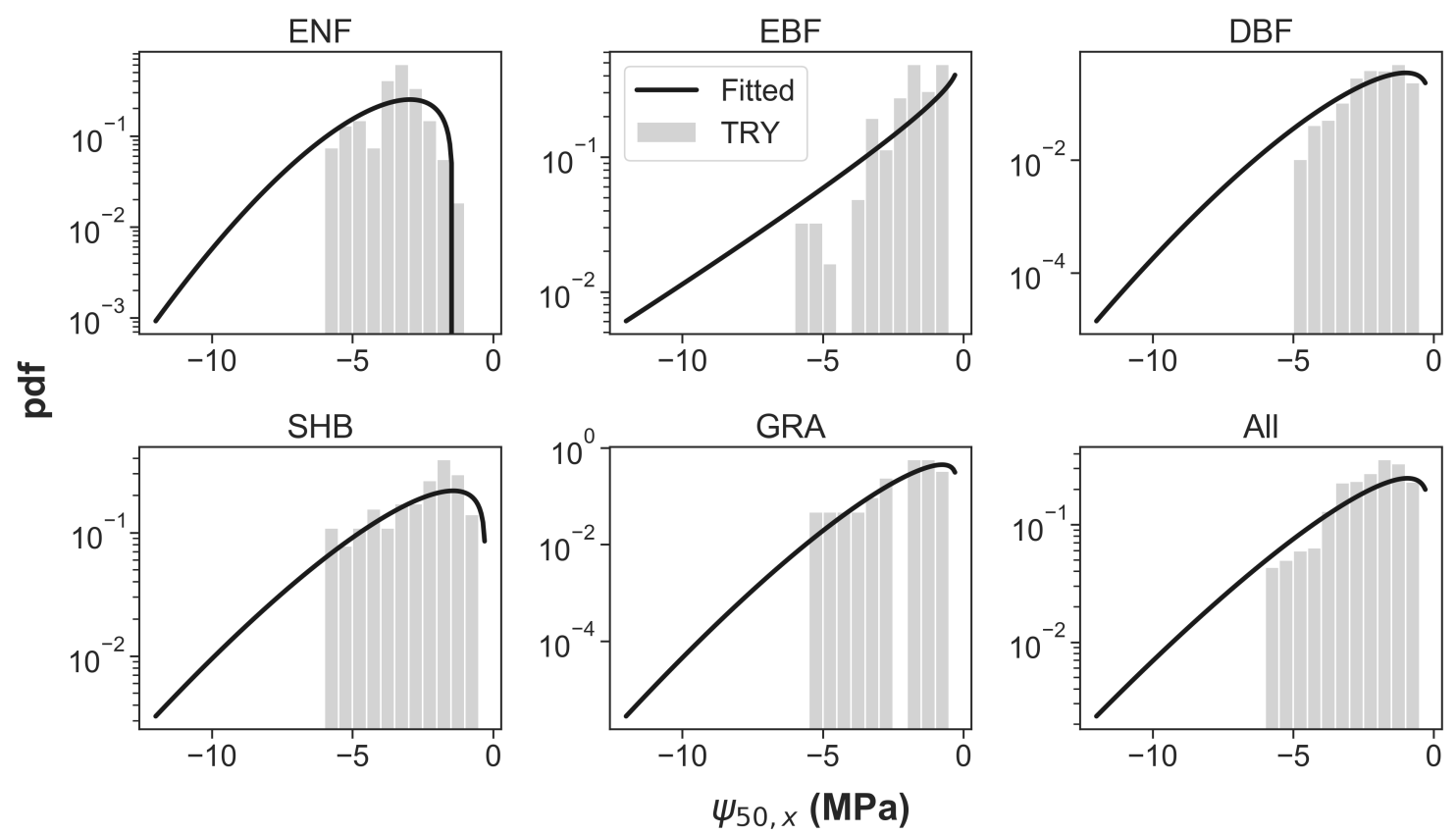

Figure S1. Generalized extreme value distributions of $\psi_{50, x}$ fitted using measurements for species belonging to the major PFTs and all species in the TRY database, used as priors in MCMC. See Fig. S2 caption for PFT acronyms. SHB includes both CSH and OSH. 

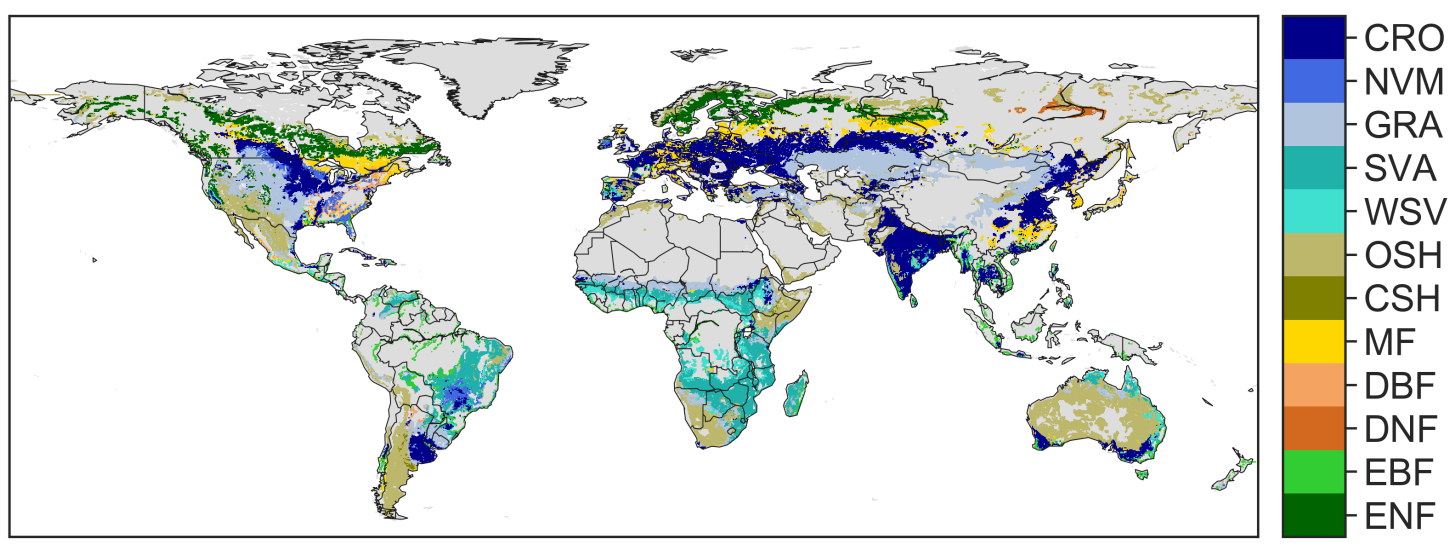

Figure S2. Global map of plant functional types based on GLDAS vegetation mask, including evergreen needleleaf forest (ENF), evergreen broadleaf forest (EBF), deciduous needleleaf forest (DNF), deciduous broadleaf forest (DBF), mixed forest (MF), closed shrublands (CSH), open shrublands (OSH), woody savannas (WSV), savannas (SVA), grassland (GRA), natural vegetation mosaic (NVM), and cropland (CRO). Grey shaded area is not include in the study. 
a

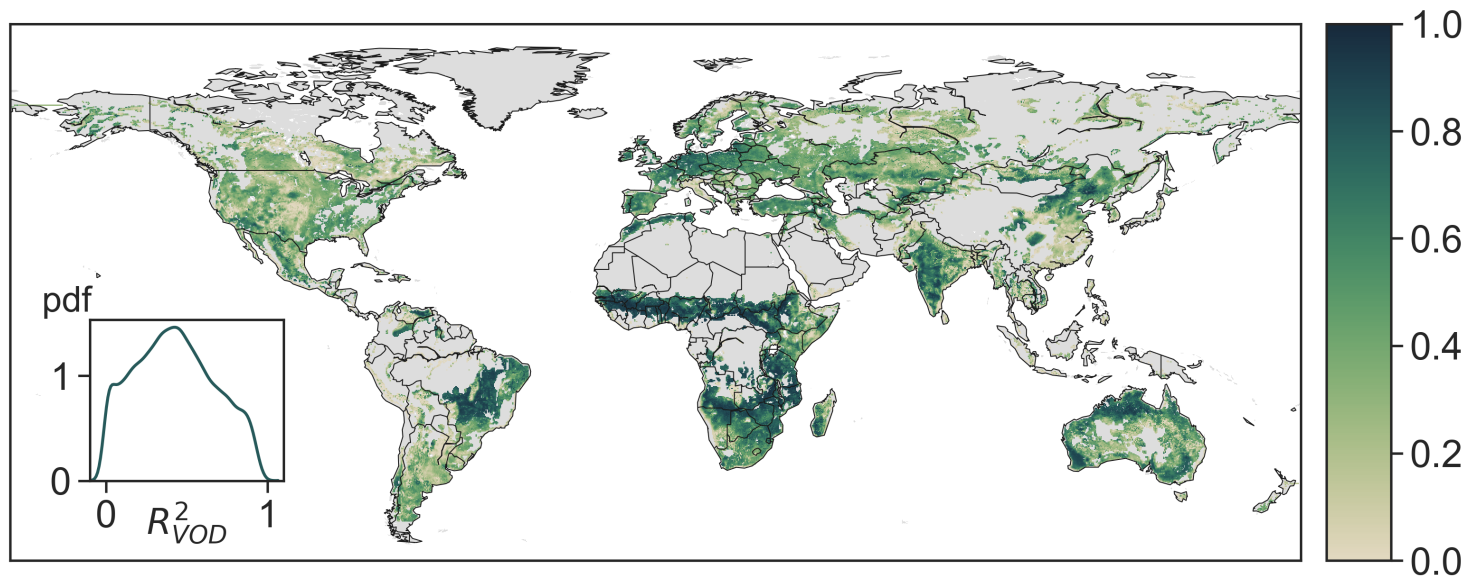

b

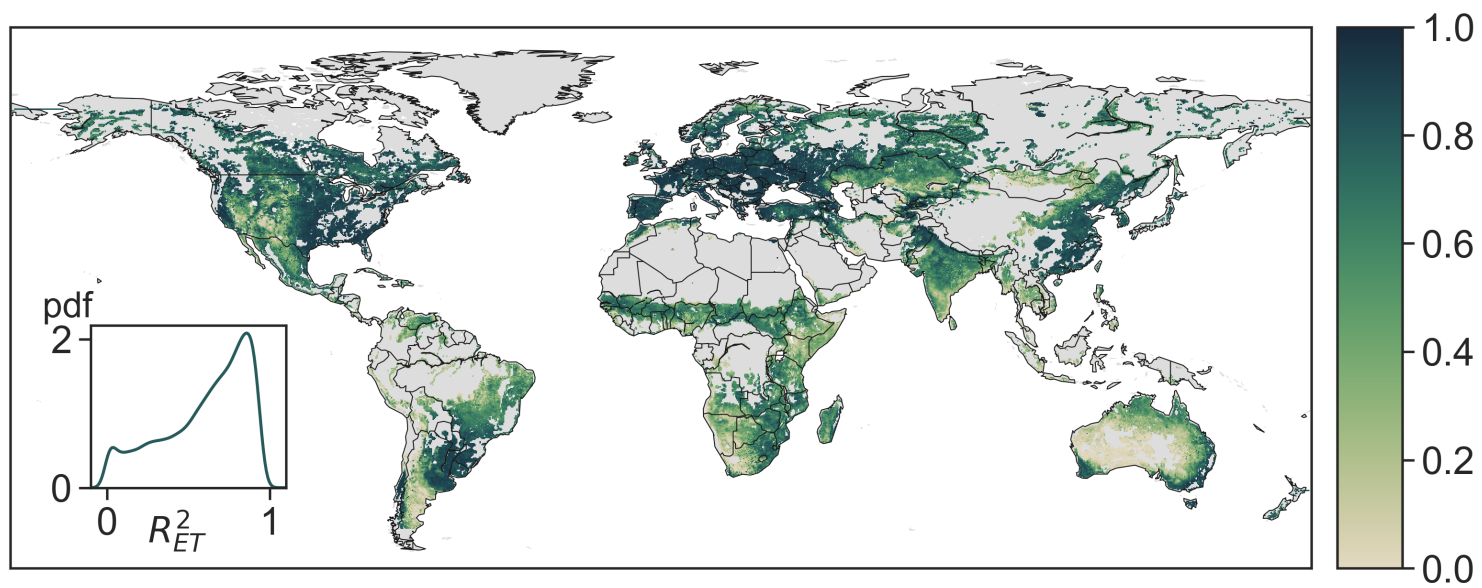

C

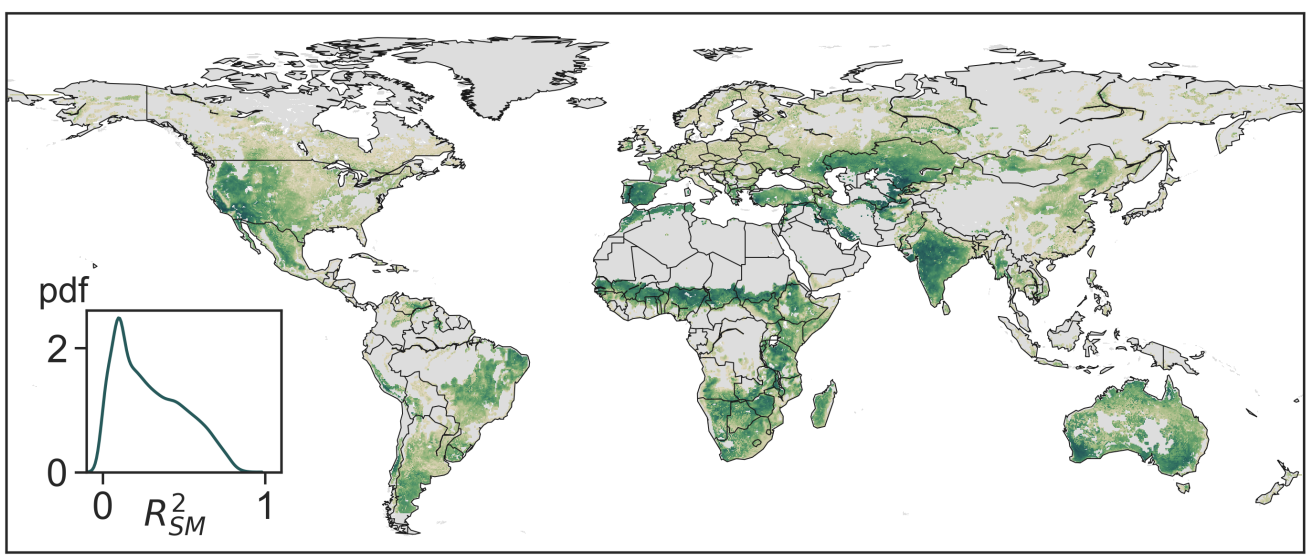

Figure S3. Assimilation accuracy $\left(\mathrm{R}^{2}\right)$ of (a) VOD, (b) ET, and (c) soil moisture during the training period 2004-2005. Insets show the probability distribution of $\mathrm{R}^{2}$ across the entire study area. Gray shaded area is not included in analysis. 


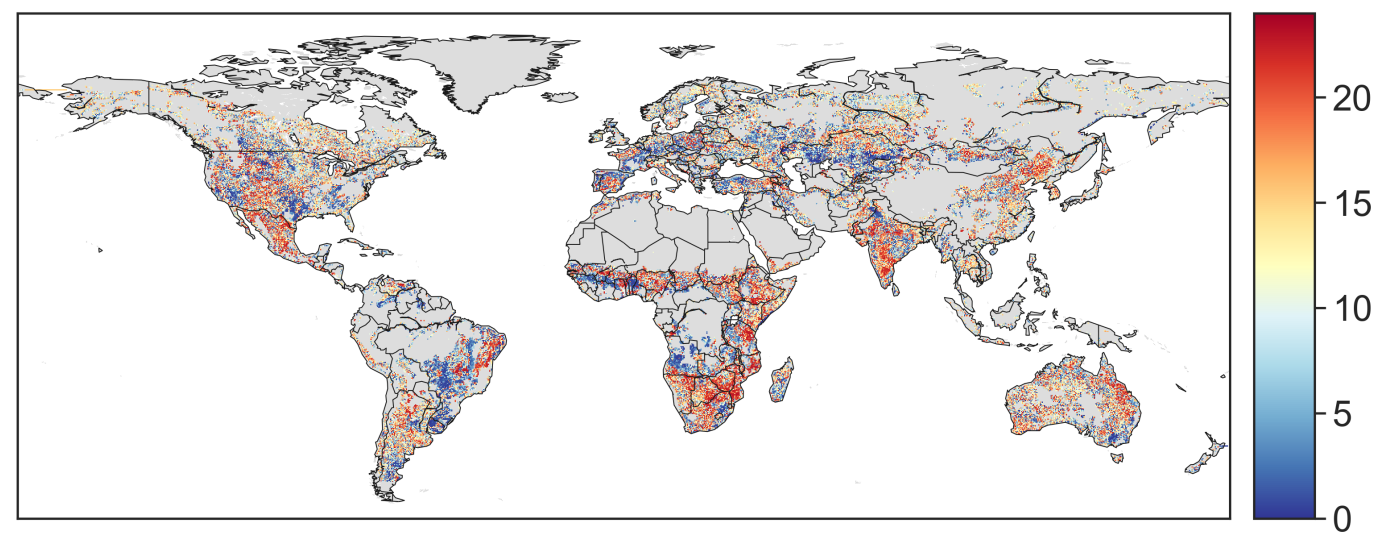

b

$\psi_{50, s}(\mathrm{MPa})$

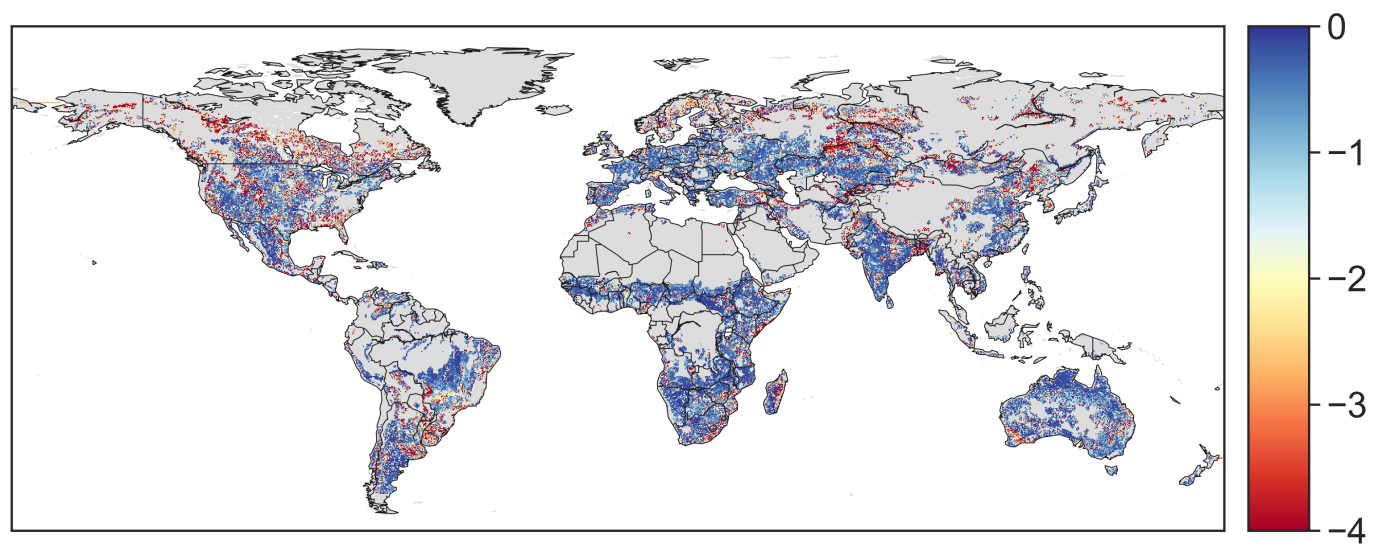

C

$g_{p, \max }\left(\mathrm{mm} \mathrm{hr}^{-1} \mathrm{MPa}^{-1}\right)$
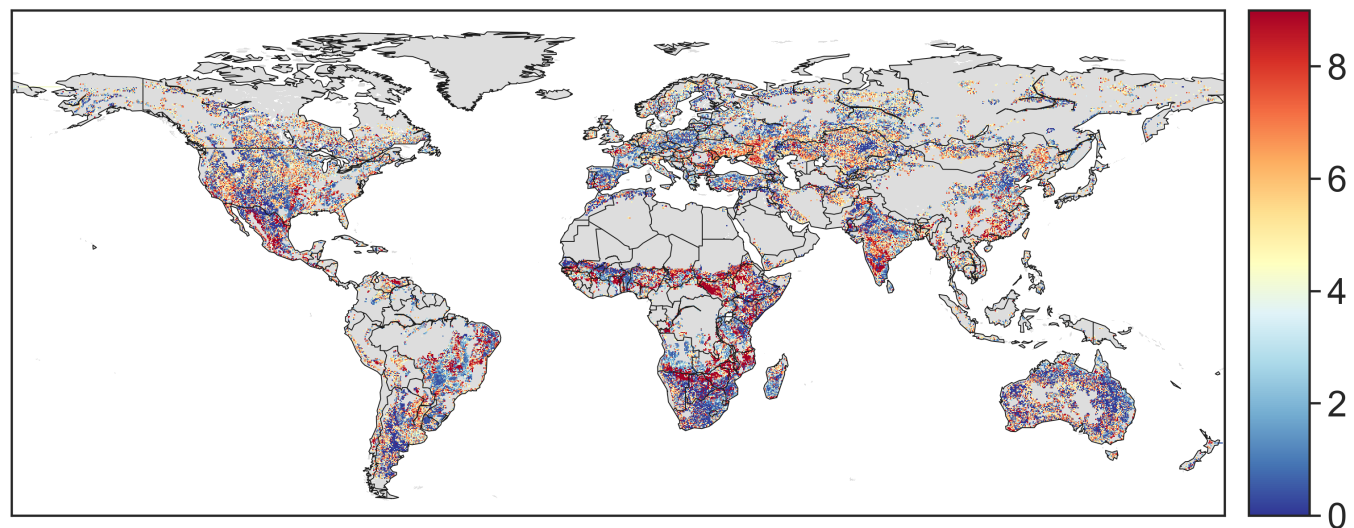

Figure S4. Global maps of the plant hydraulic traits, (a) $C$, (b) $\psi_{50, s}$, and (c) $g_{p, \max }$, retrieved using model-data fusion. Posterior mean of each pixel is plotted. 


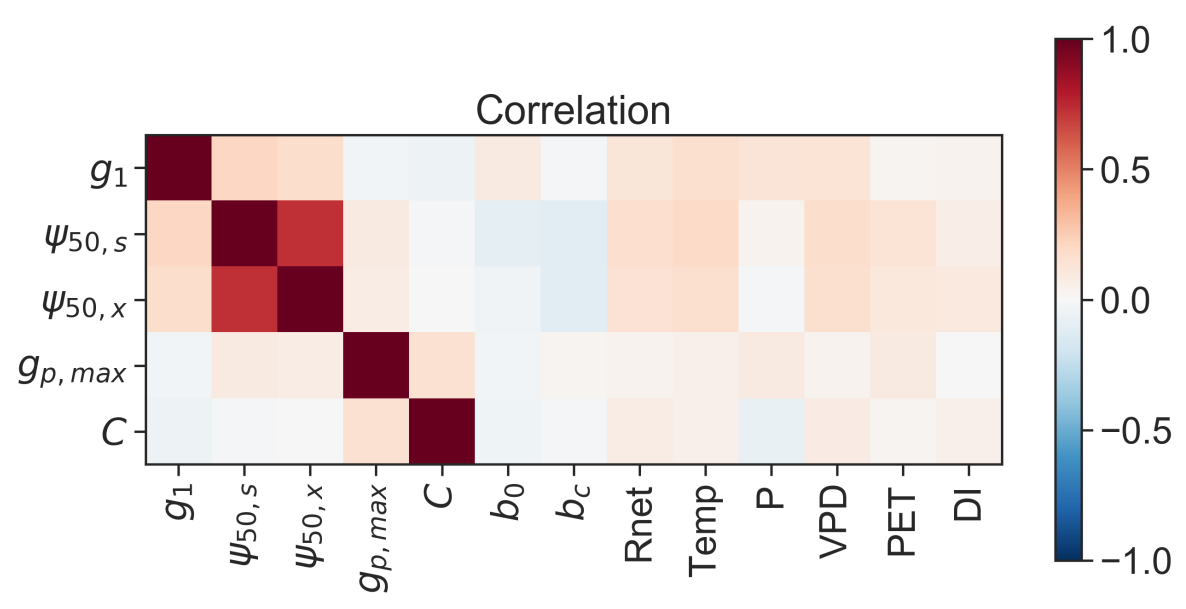

Figure S5. Correlations across pixels among the retrieved plant hydraulic traits $\left(g_{1}, \psi_{50, s} / \psi_{50, x}, \psi_{50, x}, g_{p, \text { max }}, C\right)$, soil properties $\left(b_{0}, b_{c}\right)$, and annual average climate conditions of all pixels, including net shortwave radiation (Rnet), air temperature (Temp), precipitation (P), vapor pressure deficit (VPD), potential evapotranspiration (PET) and dryness index (DI) calculated as PET/P.

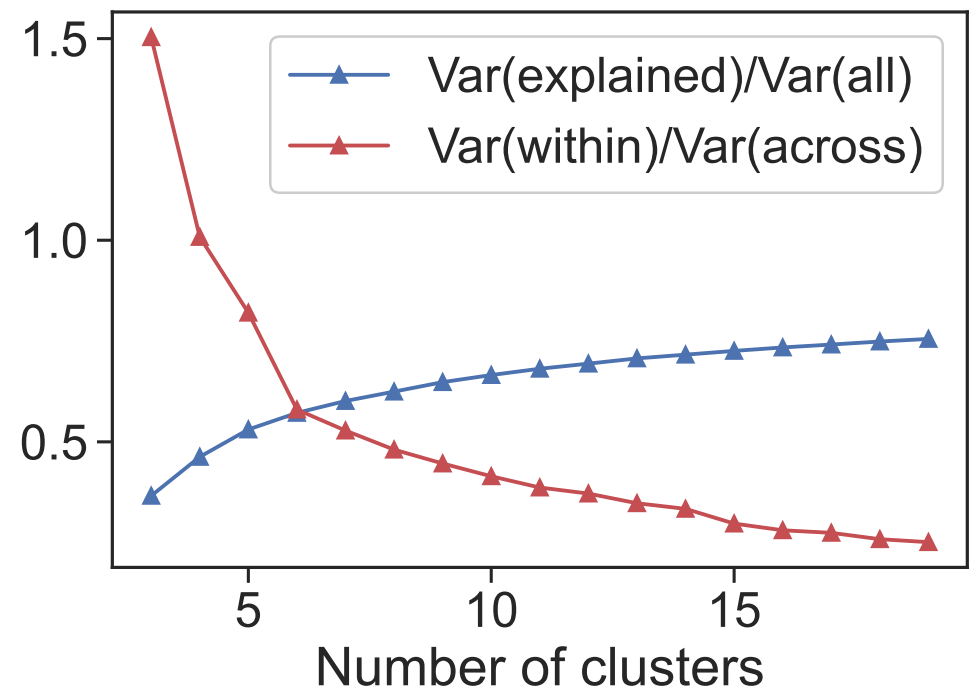

Figure S6. Relations between the number of clusters used in the K-means clustering and the fraction of explained variance (blue line) and the ratio of within- and across-cluster variances (red line) of the five plant hydraulic traits in all pixels. 